\title{
RESULTADOS DE TESTE TUBERCULINICO EFETUADO TRES MESES APÓS VACINAÇÃO, POR MEIO DO BCG ADMINISTRADO PELA VIA INTRADÉRMICA, DE PESSOAS COM IDADES DIVERSAS E RESIDENTES EM SÃO PAULO, SP (BRASIL)
}

\author{
Vicente Amato Neto * \\ Carlos Eduardo Margaritelli * \\ Gabriel Wolf Oselka* \\ Guido Carlos Levi** \\ João Silva de Mendonça** \\ Mauro Brasil Lambert dos Santos***
}

RSPUB $9 / 434$

\begin{abstract}
Amato Neto, V. et al. Resultados de teste tuberculínico efetuado três meses após vacinação, por meio do BCG administrado pela via intradérmica, de pessoas com idades diversas e residentes em São Paulo. Rev. Saúde públ., S. Paulo, $12: 471-5,1978$.

RESUMO: Foram analisados os resultados de teste tuberculínico, efetuado três meses após vacinação com BCG (amostra Moreall-Rio de Janeiro), pela via intradérmica. A casuistica correspondeu a 7.790 pessoas, incluindo as de grupo pertinente ao primeiro trimestre de vida e merecedor, atualmente, de especial atenção. Ficou constatada, globalmente, a percentagem de positividade de $69 \%$. Houve apreciação, especifica e detalhada, referente a individuos de idades diversas, e a abordagem do tema tornou-se oportuna em face ao interesse que esse tipo de imunização vem despertando no Brasil e, também, em virtude da necessidade de coletar informes aptos a apoiar trabalhos profilaticos.
\end{abstract}

UNITERmos: Tuberculose. Vacinação BCG intradérmica. Teste tuberculinico, S. Paulo, SP, Brasil.

I N T RODUCAO

No Brasil, o BCG foi usado durante muitos anos, para combater a tuberculose, quase que exclusivamente pela via oral. Não ocorreu utilização suficientemente ampla e, na verdade, esse recurso imunitário nunca determinou marcantes benefícios ou consumou qualquer impacto. Morbidade, prevalência e índice de infecção persistem elevados, tendo a mortalidade diminuído, em virtude da disponibilidade de melhores recursos terapêuticos.

Preparação liquida de $B C G$, com reduzido período de validade e requerendo conservação em baixa temperatura, de fato não

* Da Faculdade de Medicina da Universidade de São Paulo. Caixa Postal 8091 - 01000 São Paulo, SP - Brasil.

* Do Hospital do Servidor Público Estadual "Francisco Morato de Oliveira". Rua Pedro de Toledo, 1800 - 04039 - Săo Paulo, SP - Brasil.

*** Do Hospital Brigadeiro (Instituto Nacional de Assistência Médica da Previdência Social). Av. Brigadeiro Luiz Antonio, 2651 - 01401 - São Paulo, SP - Brasil. 
AMATO NETO, V. et al. Resultados de tește tuberculínico efetuado três meses após vacinação, por meio do BCG administrado pela via intradérmica, de pessoas com idades diversas e residentes em Săo Paulo, SP (Brasil). Rev. Saúde públ., S. Paulo, 12:471-5, 1978.

pode ser suficientemente útil, mormente se levada em conta a enorme extensão do território brasileiro. Parece cabível acreditar que arrefecimento da tuberculose sucederá com a melhoria das condições de vida e de habitação, em contexto no qual vacina tem condição de auxiliar em programas profiláticos. Entretanto, administração parenteral dos recursos protetores afigura-se mais recomendável, em coerência, inclusive, com o que já sucede em grande número de países.

Desde há pouco tempo emprego intradérmico do BCG tornou-se mais comum no Brasil, fazendo parte em algumas oportunidades de projetos preventivos, de preferências em clínicas privadas e de recomendação pelo Programa Nacional de Imunizações.

Em face à citada preconizaçāo que passou a tomar corpo nos últimos anos, fica evidente a necessidade de registrar e divulgar observações concernentes à aplicação do BCG pela via intradérmica, sobretudo a fim de permitir comparações entre acontecimentos relativos a regiões diferentes e a nações diversas. Assim sendo, consideramos conveniente relatar fatos que apuramos, em 'São Paulo, ao vacinar $\mathbf{7 . 7 9 0}$ pessoas de bom nivel sócio-econômico.

\section{MATERIAL E METODOS}

Injetamos, por meio de seringa e agulha, vacina preparada na Fundação Ataulpho de Paiva* com a amostra Moreau-Rio de Janeiro, segundo metodologia recomendada pela Organização Mundial da Saúde, a 7.790 indivíduos de bom nível sócio-econômico, presumivelmente não doentes e com idades diversas, atendidos em nosso Serviço privado de imunizações, com finalidade exclusivamente profilática. Não detectamos deficiências imunológicas e, outrossim, eventuais existências delas não chegaram ao nosso conhecimento. Inoculamos $0,1 \mathrm{ml}$ na derma do braço direito, ao nível da inserção inferior do músculo deltóide. Respeitamos rigorosamente o prazo de validade anotado no frasco contendo o material liofilizado e as diretrizes técnicas recomendadas, incluindo o trabalho em ambiente protegido da luz solar ou difusa.

$A$ avaliação através de intradermorreação (PPD, Rt - 23, 2 UT) sucedeu 90 dias após. Esse mesmo exame não foi executado, como triagem, antes do uso do BCG, se as crianças tinham até três meses; nos demais imunizados, negatividade prévia havia sido comprovada.

Detalhes da distribuiçāo etária dos constituintes da casuística encontram-se na Tabela 1 .

\section{RESULTADOS}

Nossas constatações estão nas Tabelas 1 e 2.

Como fatos fundamentais, destacamos a percentagem global de $69 \%$ de "viragem" do teste tuberculínico, notada em casuistica não desprezivel, e o predomínio de reatores fracos (nódulos com 4 a $9 \mathrm{~mm}$ ), especialmente presentes no grupo das crianças com até três meses de idade. Nos indivíduos com 4 a 38 meses a positividade da prova cutânea apresentou-se maior $(72 \%$ a $75 \%)$, com evidência de números mais elevados, se bem que ainda discretos, de fortes reatividades (nódulos com $10 \mathrm{~mm}$ ou maiores). O último conjunto, das pessoas com 4 anos no mínimo, fica registrado sem outros comentários porque é heterogêneo no que diz respeito ao aspecto etário.

Nos reatores fortes, apresentaram-se com mais habituais os nódulos com 10 ou $11 \mathrm{~mm}$

* Departamento de Vacinação BCG (Instituto Viscondessa de Moraes), Avenida Pedro II n" 260, Rio de Janeiro, Brasil; cada $\mathrm{ml}$ contém $1 \mathrm{mg}$ de bacilos após adição de solução fisiológica e obtenção de suspensão homogênea; depois de reconstituição, deve conter mais de um milhão de germes vivos por $0,1 \mathrm{ml}$. 
AMATO NETO, V. et al. Resultados de teste tuberculinico efetuado três meses após vacinação, por meio do BCG administrado pela via intradérmica, de pessoas com idades diversas e residentes em São Paulo, SP (Brasil), Rev. Saúde públ., S. Paulo, 12:471-5, 1978.

\section{T A B E L A 1}

Teste tuberculínico (PPD, Rt-23, 2 UT) efetuado três meses após vacinação, por meio de BCG administrado pela via intradérmica, de pessoas com idades diversas e residentes em São Paulo: casuística e resultados

\begin{tabular}{|c|c|c|c|c|c|}
\hline \multirow{2}{*}{$\begin{array}{c}\text { Idade } \\
\text { (meses) }\end{array}$} & \multirow{2}{*}{$\begin{array}{l}\text { Número de } \\
\text { vacinados }\end{array}$} & \multicolumn{3}{|c|}{ Resultados do teste tuberculínico } & \multirow{2}{*}{$\begin{array}{l}\text { Número e } \\
\text { percentagem de } \\
\text { reatores }\end{array}$} \\
\hline & & $\begin{array}{l}\text { Não } \\
\text { reatores }\end{array}$ & $\begin{array}{c}\text { Reatores } \\
\text { fracos }\end{array}$ & $\begin{array}{l}\text { Reatores } \\
\text { fortes }\end{array}$ & \\
\hline Até $3 \mathrm{~m}$ & 1.727 & 666 & 887 & 174 & $1.061(61 \%)$ \\
\hline 4 a $12 \mathrm{~m}$ & 2.102 & 521 & 1.137 & 444 & $1.581(75 \%)$ \\
\hline 13 a $38 \mathrm{~m}$ & 2.679 & 729 & 1.341 & 609 & $1.950(72 \%)$ \\
\hline $\begin{array}{l}\text { Superior } \\
\text { a } 38 \mathrm{~m}^{*}\end{array}$ & 1.282 & 479 & 534 & 251 & $785 \quad(61 \%)$ \\
\hline Total & 7.790 & 2.413 & 3.899 & 1.478 & $5.377(69 \%)$ \\
\hline
\end{tabular}

* Desde pré-escolares até adultos com diversas idades.

T A B EL A 2

Teste tuberculínico (PPD, Rt-23, 2 UT) efetuado três meses após vacinação, por meio de BCG administrado pela via intradérmica, de pessoas com idades diversas e residentes em São Paulo: reatores fracos e fortes

\begin{tabular}{|c|c|c|c|c|}
\hline \multirow{2}{*}{$\begin{array}{c}\text { Idade } \\
\text { (meses) }\end{array}$} & \multicolumn{2}{|c|}{ Reatores fracos } & \multicolumn{2}{|c|}{ Reatores fortes } \\
\hline & $\mathrm{N}$ & $\%$ & No & $\%$ \\
\hline Até $3 \mathrm{~m}$ & 887 & 51 & 174 & 10 \\
\hline 4 a $12 \mathrm{~m}$ & 1.137 & 54 & 444 & 21 \\
\hline 13 a $38 \mathrm{~m}$ & 1.341 & 50 & 609 & 22 \\
\hline Superior a $38 \mathrm{~m}$ * & 534 & 41 & 251 & 19 \\
\hline Total & 3.899 & 50 & 1.478 & 18 \\
\hline
\end{tabular}

* Desaje pré-escolares até aduitos com diversas idades.

Manifestações colaterais dignas de menção não ocorreram. Apenas deparamos com a usual evolução do processo cutâneo decorrente da aplicação intradérmica do BCG, valendo a pena lembrar que sempre inoculamos $0,1 \mathrm{ml}$; não injetamos $0,05 \mathrm{ml} \mathrm{em}$ recém-nascidos, convém frizar, como preferem outros profissionais.

\section{DISCUSSÃO}

É apropriado comparar nossas verificaçōes com as de outros profissionais que efetuaram estudos congêneres.

Certain e col. ${ }^{3}$ vacinaram escolares, pela via intradérmica, na cidade de São Paulo, utilizando preparação produzida na Inglaterra. Detectaram, decorridas dez semanas, 
AMATO NETO, V. et al. Resultados de teste tuberculínico efetuado três meses após vacinação. por meio do BCG administrado pela via intradérmica, de pessoas com idades diversas e residentes em São Paulo, SP (Brasil). Rev. Saúde pübl., S. Paulo, 12:471-5, 1978.

$92,3 \%$ de resultados positivos ao reteste, que mais comumente identificou fortes reatividades $(86 \%)$. Ao comunicar os eventos da investigação que levaram a cabo, infelizmente não citaram se recorreram a material liquido ou liofilizado, assim como deixaram de esclarecer qual a dose aconselhada e qual o teor, em unidades, de PPD injetado.

Por seu turno, Brólio e col. ${ }^{2}$, com preparado imunizante liofilizado, inoculado em escolares, não reatores, da série inicial do primeiro grau, também residentes em São Paulo, perceberam a ocorrência de $85,7 \%$ de provas, fracas $(16,4 \%)$ e fortes $(69,3 \%)$, positivas. Utilizaram igualmente vacina procedente da Inglaterra ("Laboratório Glaxo") e presumivelmente administraram $0,1 \mathrm{ml}$, tendo medido a sensibilidade tuberculínica por meio de PPD, Rt-23, $2 \mathrm{UT}$

Novecentas e cinco crianças sadias, com um, dois ou três meses de idade, receberam intradermicamente vacina BCG elaborada com a amostra Moreau-Rio de Janeiro e liofilizada, em pesquisa executada por Amato Neto e Finger ${ }^{1}$. A dose usada correspondeu a $0,1 \mathrm{ml}$ e essa quantidade deve conter mais de um milhão de germes vivos. Para avaliar a efetividade da imunização, teste tuberculínico foi praticado com PPD, Rt-23, 2 UT, 90 dias após ou em época com duração superior a essa, sem ultrapassar, no entanto, dez meses. Como dedução fundamental, constataram a percentagem de positividade de $63,2 \%$, inferior à registrada, no mesmo ambiente, em relação a escolares, conforme antes ficou relatado.

Como ficou evidente, coletamos informes diferentes dos consignados por Certain e

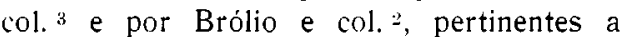
escolares de São Paulo. Em suma, apuramos menores cifras de intradermorreaçóes positivas e de reatividades fortes. No entanto, relativamente aos infantes com até três meses, obtivemos valores semelhantes aos comunicados por Amato Neto e Finger ${ }^{1}$, que realizaram estudo no Hospital do Servidor Público Estadual "Francisco $\mathrm{Mo}^{-}$ rato de Oliveira", de caráter previdenciário e que atende servidores do Governo do Estado e seus dependentes. Trabalhamos na mesma cidade de São Paulo e vacinamos, em clinica privada, individuos de nivel igual ou algo superior, comparativamente aos englobados na investigação pouco antes referida.

Amato Neto, V. et al. RResults of tuberculin tests performed three months after $B C G$ intradermal vaccination on persons of various ages residing in $S$. Pallo, Brazil] Rev. Saúde públ., S. Paulo, 12:471-5, 1978.

ABSTRACT: Results of tuberculin skin tests performed three months after intradermal vaccination with the Moreau-Rio de Janeiro strain of BCG were analyzed. The tests were made upon 7,790 persons, including a group of infants in their first trimester of life, a delicate and obviously necessary object of attention today. The percentage of positive reactors in the whole population group tested was $69 \%$. A detailed analysis of the reactiveness in the different age groups was carried out. Moreover, that this study is opportune has been stressed not only because of the rising interest in Brazil in this type of immunization but also because of the need to compile information supporting prophylactic action.

UNITERMS: Tuberculosis. BCG vaccination, intradermic. Tuberculin test, S. Paulo, SP, Brazil. 
AMATO NETO, V. et al. Resultados de teste tuberculínico efetuado três meses após vacinação, por meio do BCG administrado pela via intradérmica, de pessoas com idades diversas e residentes em São Paulo, SP (Brasil), Rev. Saúde públ., S. Paulo, 12:471-5, 1978.

\section{REFERENCIAS BIBLIOGRAFICAS}

1. AMATO NETO, V. \& FINGER, H. Avaliação, por meio de teste tuberculinico realizado precocemente, da efetividade de imunização com vacina BCG administrada, pela via intradérmica, a crianças sadias com no máximo três meses de idade, residentes na cidade de São Paulo, Rev. goiana Med., 22: $87-90,1976$.

2. BRólio, R. et al. Programa desenvolvido na pesquisa da sensibilidade tuberculínica e vacinação pelo $B C G$ intradér- mico, em escolares do primeiro ano da Rede Municipal de Ensino de Sto Paulo, durante $o$ ano de 1971. Rev. Div. nac. Tuberc., 18:46-52, 1974.

3. Certain, D. A. et al. Ensaio de BCG intradérmico em escolares de São Paulo, Capital - 1970. Rev. Div. nac. Tuberc., 15:281-7, 1971.

Recebido para publicaça em 26/07/1978 Aprovado para publicaçáo em 09/08/1978 